\title{
Assessment of myocardial blood perfusion improved by CD151 in a pig myocardial infarction model
}

\author{
Hou-juan ZUO, Zheng-xiang LIU*, Xiao-chun LIU, Jun YANG, Tao LIU, Sha WEN, Dao-wen WANG, Xin ZHANG \\ Department of Cardiology of Tongji Hospital, Tongii Medical College, Huazhong University of Science and Technology, Wuhan 430030, China
}

\begin{abstract}
Aim: To appraise the efficacy of CD151-induced myocardial therapeutic angiogenesis in a pig myocardial infarction model. Methods: CD151 and anti-CD151 were constructed into the recombinant adeno-associated virus (rAAV) vector. All 26 pigs were subjected to coronary artery ligation or no surgery. Eight weeks after coronary artery ligation, the expression of CD151 was measured by Western blot and immunostaining. Capillary density was evaluated using immunostaining for von Willebrand factor (vWF). ${ }^{13} \mathrm{~N}$-labeled $\mathrm{NH}_{3}$ positron emission computed tomography $\left(\left[{ }^{13} \mathrm{~N}\right] \mathrm{NH}_{3} \mathrm{PET}\right)$ was measured to assess regional myocardial perfusion and the defect area.

Results: CD151 gene delivery could increase the expression of CD151 at protein level. Over-expression of CD151 increased the density of total capillaries in the ischemic myocardium, significantly improved the blood perfusion and reduced the defect area percentage.

Conclusion: This study demonstrated that the rAAV-mediated CD151 gene delivery promoted efficient neovascularization and increased the blood perfusion after myocardial infarction in pigs.
\end{abstract}

Keywords: gene therapy; CD151; neovascularization; emission-computed; $\mathrm{NH}_{3}$

Acta Pharmacologica Sinica (2009) 30: 70-77; doi: 10.1038/aps.2008.10; published online 15th December 2008

\section{Introduction}

Gene therapy is a potential new treatment for patients unsuitable for conventional revascularization strategies. Myocardial ischemia is one of the most promising targets of gene therapy. A large amount of experimental data evaluated in various animal studies have shown the benefit of therapeutic angiogenesis, which make the restoration of myocardial blood flow become possible after myocardial ischemia ${ }^{[1,2]}$.

CD151 (also known as PETA-3 or SFA-1) is a member of the transmembrane 4 superfamily (TM4SF) that is comprised of four transmembrane domains, two extracellular and one intracellular loops, and $\mathrm{NH}_{2}{ }^{-}$and $\mathrm{COOH}^{-}$terminal intracytoplasmic domains ${ }^{[3,4]}$. CD151 protein is expressed in various cell types including epidermal basal cells, epithelial cells, skeletal, smooth and cardiac muscle, endothelial cells, platelets, and schwann cells ${ }^{[5]}$. Coimmunoprecipitation of CD151 shows its association with $\beta 1, \beta 3, \beta 4, \alpha 2, \alpha 3, \alpha 5$, and $\alpha 6$ integrin chains ${ }^{[6]}$. Several studies have demonstrated

* Correspondence to Prof Zheng-xiang LIU.

E-mail liuzhengxiang@hotmail.com

Received 2008-07-18 Accepted 2008-10-20
CD151 and integrins form $\alpha 6 \beta 4, \alpha 6 \beta 1, \alpha 3 \beta 1$ complexes, and the CD151- $\alpha 3 \beta 1$ integrin complex unusually has high stoichiometry, proximity and stability ${ }^{[6,7]}$. Based on the structural properties of CD151, Hemler et al have proposed a "transmembrane linker" model and CD151 is reported to regulate the signal transduction through the integrin complex ${ }^{[7-9]}$.

Although the physiological function of CD151 is largely unknown, in vitro functional studies show CD151 is involved in the cell migration, spreading, adhesion and morphology ${ }^{[4-8]}$. Recent researches suggest a role of CD151 in angiogenesis. Antibody against CD151 protein inhibits the migration of endothelial cell, decreases the ability of endothelial cells to invade Type I collagen gels, and inhibits in vitro capillary formation ${ }^{[6,8,10]}$. The human umbilical vein endothelial cells (HUVEC) transfected with CD151 have increased ability of proliferation, migration and cable formation on matrigel ${ }^{[11,12]}$. Our group has shown that in vivo CD151 gene delivery increases the number of microvessels in a rat hind-limb ischemia model and a rat myocardial ischemia mode ${ }^{[13,14]}$. These researches have identified CD151 as a potential target for therapeutic angiogenesis.

The aim of gene therapy is focused more on enhancing 
collateral vessel growth, thereby increasing blood flow, than on increasing the number of microvessels ${ }^{[1,15]}$. However, whether CD151-induced neovascularization can effectively promote the blood flow is still unclear. To further research, the purpose of present study was to determine the myocardial perfusion of the rAAV-mediated CD151 gene delivery in a pig acute myocardial infarction (AMI) model.

\section{Materials and methods}

Materials PzeoSV-CD151 plasmid was given as a gift by Dr Xin ZHANG, Department of Molecular Science, University of Tennessee Health Science Center (Memphis, Tennessee, USA). Goat anti-human CD151 and mouse anti- $\beta$-actin antibody were purchased from Santa Cruz Biotechnology (Santa Cruz, California, USA). Mouse anti-vWF was from Invitrogen (Boston, USA). Enhanced chemiluminescnet (ECL) substrate was from Pierce (Rockford, Illinois, USA). Dulbecco's modified Eagle's medium (DMEM) culture medium was purchased from Gibco (Los Ageles, CA, USA). $\left[\alpha^{32} \mathrm{P}\right]$-dCTP $(3000 \mathrm{Ci} / \mathrm{mmol})$ was from Rui FU Biological Engineering Company Nucleic acid Laboratory (Beijing, China).

Preparation of rAAVs and quantitation of viral titers The construction of $\mathrm{rAAV}$ vector plasmid dsAAV-CD 151 and dsAAV-antiCD151 had been described before ${ }^{[16]}$. The packing and production of the rAAV-GFP, rAAV-CD151 and rAAV-antiCD151 were carried out using a triple-plasmid cotransfection method in 293 cell lines ${ }^{[17]}$. The cells can be transfected at $70 \%$ to $80 \%$ confluence. A total of $85 \mathrm{mg}$ of plasmid DNA (the molar ratios of dsAAV-GFP or dsAAVCD151 or dsAAV-antiCD151 to pXX2 and pHelper were $1: 1: 1)$ was dissolved in $0.25 \mathrm{~mol} / \mathrm{L} \mathrm{CaCl}_{2}$, quickly mixed with $2 \times$ BES [N,N-bis(2-hydroxyethy) taurine]-buffered saline, and added to the cells in $15-\mathrm{cm}$ plate. The cells were harvested at 48 to $72 \mathrm{~h}$ after transfection. After 3 cycles of freeze-thaw and centrifugation, the rAAVs were remained in supernatant. Then the single step gravity-flow column purification was applied. The eluted rAAVs were divided into aliquots and stored at $-80^{\circ} \mathrm{C}$. The titer of vector particles was determined by the quantitative DNA dot-blot hybridization.

Myocardial infarction and intramyocardial gene delivery A model of AMI was created in 3-month-old male pigs (Animal Apply Center, Huazhong Agriculture College, Wuhan, China) weighing $(24 \pm 2) \mathrm{kg}$. Animals were randomly divided into 4 groups but 3 groups underwent coronary artery ligation. Briefly, pigs were sedated with intramuscular diazepam $(0.05 \mathrm{mg} / \mathrm{kg})$, atropine $(0.05 \mathrm{mg} / \mathrm{kg})$, ketamine $(20 \mathrm{mg} / \mathrm{kg})$, intubated, and sedation was maintained with thiopental sodium $\left(2.5-4 \mathrm{mg} \cdot \mathrm{kg}^{-1} \cdot \mathrm{h}^{-1}\right)$ and pancuronium (0.1-0.15 $\left.\mathrm{mg} \cdot \mathrm{kg}^{-1} \cdot \mathrm{h}^{-1}\right)$. A limited left thoracotomy was performed in a sterile fashion through the fifth intercostal space and a small incision was made in the pericardium. The heart was exposed and suspended in a pericardial sling. A silk suture was set at 1/3 marginal branch of the left anterior descending (LAD) coronary artery and ligated 20 min later. Proper occlusion of the coronary artery resulted in AMI comprising a major part of the left ventricle free wall, with small variations in size. Coronary occlusion was confirmed by the presence of raised ST stages on the electrocardiogram and ventricular arrhythmias within the 1st 20-30 min after occlusion.

Four groups were assigned as control group (normal pigs), rAAV- GFP group ( AMI+ rAAV-GFP), rAAV-CD151 group (AMI+ rAAV-CD151) and rAAV- antiCD151 group (AMI+ rAAV-antiCD151). Gene delivery was performed by direct intramyocardial injection. Each vector was injected at 10 sites, each in $200 \mu \mathrm{L}$ phosphate buffered saline solution, $\mathrm{pH} 7.4$, along the region of LAD distribution $\left(1 \times 10^{11}\right.$ $\mathrm{pfu}$ /injection). The sites of intramyocardial injection were marked with India ink for subsequent identification. The pericardium and chest were then closed and these pigs were allowed to recover. During 3 days after surgery, pigs received intramuscular penicillin 1.6 million $\mathrm{U} / \mathrm{d}$, oral Aspirin 75 $\mathrm{mg} / \mathrm{d}$. Experimental protocols complied with National Institutes of Health Guidelines for the Care and Use of Laboratory Animals and were approved by the Academy of Sciences of China.

$\left[{ }^{13} \mathrm{~N}\right] \mathrm{NH}_{3}$ PET assessment of regional myocardial perfusion $\left[{ }^{13} \mathrm{~N}\right] \mathrm{NH}_{3}$ PET was taken in all pigs 8 weeks after the vector administration. Pigs were sedated as above and anesthetia was maintained with intravenous $3 \%$ sodium pentobarbital $(30 \mathrm{mg} / \mathrm{kg}$ ). One third of the total amount was given first and $6 \mathrm{~mL}$ was added every $30 \mathrm{~min}$ according to the anesthetia conditions. Pigs were placed in the dorsal position in a Discoery LS PET/CT system (GE, USA). During anesthesia, pigs received intravenous 555-740 MBq (15-20 $\mathrm{mCi}$ ) bolus of ${ }^{13} \mathrm{~N}-\mathrm{NH}_{3}$ and were scanned 20 min later. Image analysis was acquired in an analogous fashion, strata thick $4.25 \mathrm{~mm}$, matrix $128 \times 128$, a "step-and-shoot" mode over a 180-degree body-contouring orbit. The cloud plots were constructed by nesting the ventricular short-axis images. For each animal, a summed regional ischemia score and the defect area percentage were obtained by Cardiac Toolbox.

Immunohistologic evaluation Samples were taken from the left ventricular territory around the previously marked sites. One section of every sample was stained with hematoxylin and eosin, other sections of tissue samples 
were stained for vWF and CD151. In brief, sections were deparaffinized and microwave treated for $10 \mathrm{~min}$ twice in 10 $\mathrm{mmol} / \mathrm{L}$ sodium citrate $(\mathrm{pH} 6.0)$. Endogenous peroxidase in the section was blocked by incubating them in endogenous peroxidase blocking solution for $10 \mathrm{~min}$ at room temperature. Primary antibody was at a 1:50-1:100 dilution at $4{ }^{\circ} \mathrm{C}$ for $18 \mathrm{~h}$. After washing 3 times with PBS, sections were incubated with biotin conjugated secondary antibody for 10 min. They were then washed 3 times with PBS, treated with streptavidin peroxidase for $10 \mathrm{~min}$, and washed again with PBS 3 times. Finally, specimens were incubated in DAB for 3-5 min.

The densities of capillaries were evaluated according to the methods described before ${ }^{[18]}$. The five most blood-vessel rich regions were selected, and the microvessels within $\times 400$ microscopic field of each region were counted by two investigators. The density of capillaries in each field was evaluated by counting vessels in a total of 5 high-power fields per region per heart under ocular micrometers (Olympus).

Western blot analysis Tissue samples of 4 to 6 pigs per group were taken from the infarcted area around the previously marked sites. The tissues were homogenized in 500 $\mu \mathrm{L}$ of $25 \mathrm{mmol} / \mathrm{L}$ Tris- $\mathrm{HCl}$ ( $\mathrm{pH} 7.4$ ) containing 1\% Triton $\mathrm{X}-100,0.1 \%$ SDS, $2 \mathrm{mmol} / \mathrm{L}$ EDTA, and 1\% protease inhibitor and centrifuged at $14000 \times \mathrm{g}$ for $30 \mathrm{~min}$ at $4^{\circ} \mathrm{C}$. The supernatants were used for Western blot analysis, with specific primary antibodies detecting CD151. The HRP-conjugated secondary antibodiy was used to reveal the specific protein bands with ECL detection reagents. The intensities of protein bands were quantified by densitometry.

TC staining Three pigs per AMI surgery groups were sacrificed for evaluation of regional myocardial infarct by staining with triphenyltetrazolium chloride (ТTC) (Shanghai Chemical Agent Plant, Shanghai, China). The left ventricle of each heart was sectioned into several rings $(6-7 \mathrm{~mm}$ in the thickness) in the short axis. TTC $2 \%$ was freshly prepared using PBS solution, $\mathrm{pH}$ 7.4. The staining heart slices were photoed further.

Statistical analysis Data were expressed as mean \pm SEM. Comparisons of parameters among the 4 groups were performed by one-way ANOVA, followed by Newman-Keuls test for unpaired data. Comparisons of parameters between 2 groups were made by unpaired Student's $t$ test. $P$ values of $<0.05$ were considered statistically significant.

\section{Results}

Construction of swine myocardial infarction models All of 26 animals entered into the study, 22 pigs (Control group, $n=4$; rAAV-GFP group, $n=6$; rAAV-CD 151 group, $n=6$; rAAV-antiCD151 group, $n=6$ ) survived and other 4 pigs died. The data related to the myocardial infarction in the distal LAD coronary artery region in the pigs were presented in two ways: (1) HE stainings of AMI groups showed large chaotic fibrous tissue instead of normal regular cadiocyte (Figure 1A); (2) The color of myocardial infarction area received TTC staining changed to white without being dyed, but normal myocardium area was dyed brick-red (Figure 1B).

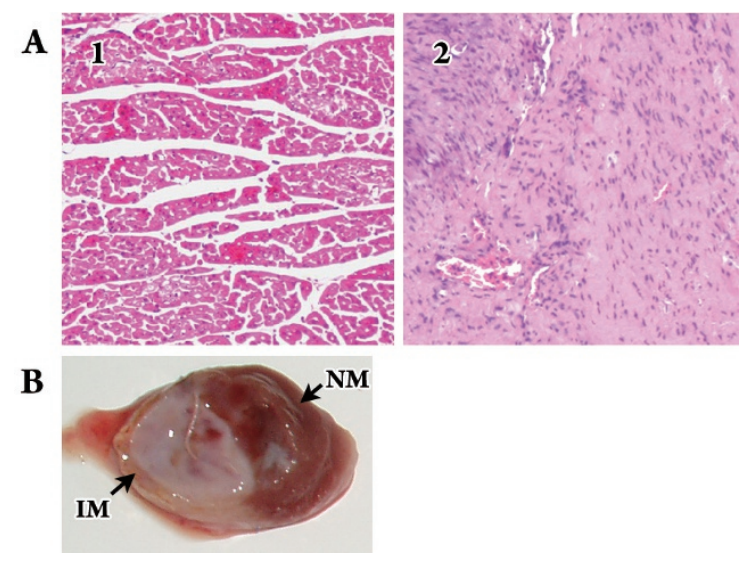

Figure 1. Myocardial infarction was observed in the pigs hearts. (A) $\mathrm{HE}$ stainings of myocardium tissue (magnification $\times 100$ ). 1, normal myocardium tissue; 2 , Infarction myocardium tissue showed large chaotic fibrous tissue. (B) TTC staining showed the apical myocardial infarction. Myocardial infarction area received ТTC staining was white, but nomal myocardium was dyed brick-red. NM, normal myocardium; IM, infarction myocardium.

\section{Expression of CD151 in different swines myocardium} Western blot showed the expression of CD151 protein was increased significantly in the rAAV-CD151 group compared with the Control group and rAAV-GFP group $(P<0.05)$, but decreased dramatically in the rAAV-antiCD151 group $(P<0.05)$. There was no significant difference of the CD151 expression between the Control and rAAV-GFP groups $(P>0.05)$ (Figure 2A, 2B).

Consistent with the Western blot results, the S-P immunostaining of CD151 showed that most vascular endothelial cells and myocardial cells were stained obviously dark brown in the rAAV-CD151 group, but the Control group and rAAVGFP group staining were mainly expressed at some vascular endothelial cells and several myocardial cells surface. rAAVantiCD 151 group staining was quite light (Figure 2C). These results indicate that rAAV-CD151 administration increases myocardium tissue CD151 protein expression. 
A

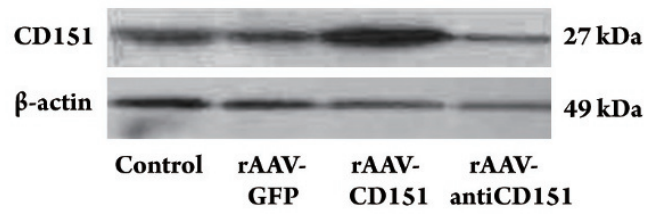

B

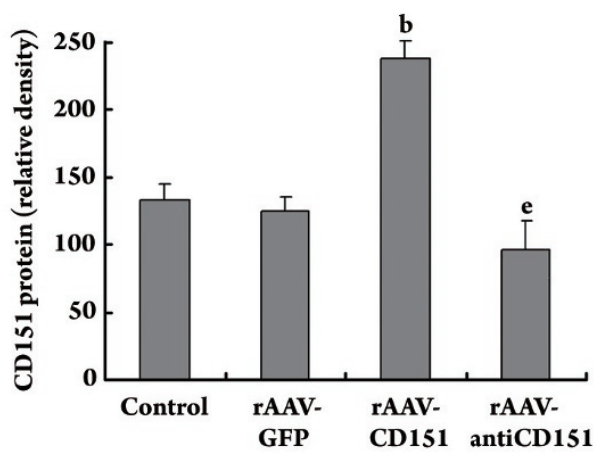

C

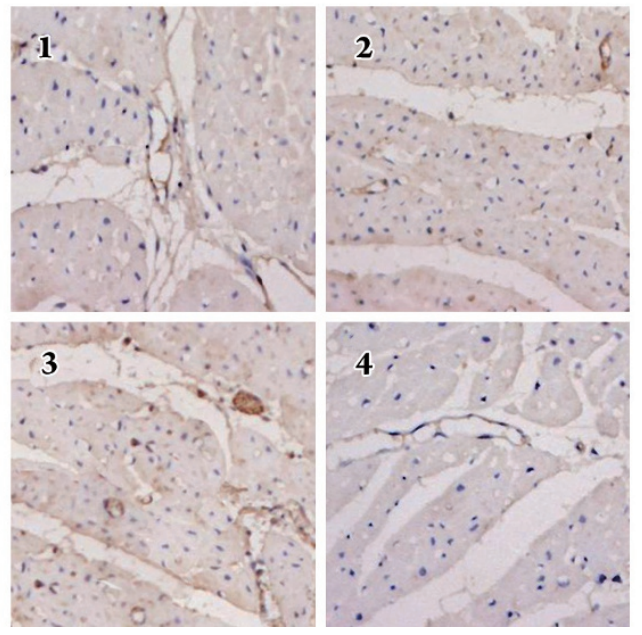

Figure 2. The expression of CD151 protein was detected in four different groups. (A) Western blot showed the protein expression of CD151 and $\beta$-actin in the hearts of different groups. $\beta$-actin was used as an internal loading control. (B) Quantitative results of CD151 protein expression. Results showed great increase in rAAV-CD151 group, but marked decrease in rAAV- antiCD 151 group. ${ }^{b} P<0.05$ vs Control and rAAV-GFP groups. ${ }^{e} P<0.05$ vs rAAV-CD 151 group. Data are as mean $\pm \operatorname{SEM}(n=4)$. (C) Sections of each group were immunostained for CD151. A representative section showed strong staining (brown) for CD151 in the rAAV-CD151 group. Faint staining was observed in the rAAV-antiCD151 group. (magnification $\times 200$ ) 1 , Control group; 2, rAAV-GFP group; 3, rAAV-CD151 group; 4, rAAVantiCD151 group.

Effect of CD151 on the myocardium capillary density Blood vessels were highlighted by immunostaining for vWF. The endothelial cell dyed brown, single or cluster, was counted as one vessel. The blood vessel whose diameter exceeded 8 akaryocyte diameters or the muscular layer was visible would not be counted in the total numbers. The den-
A
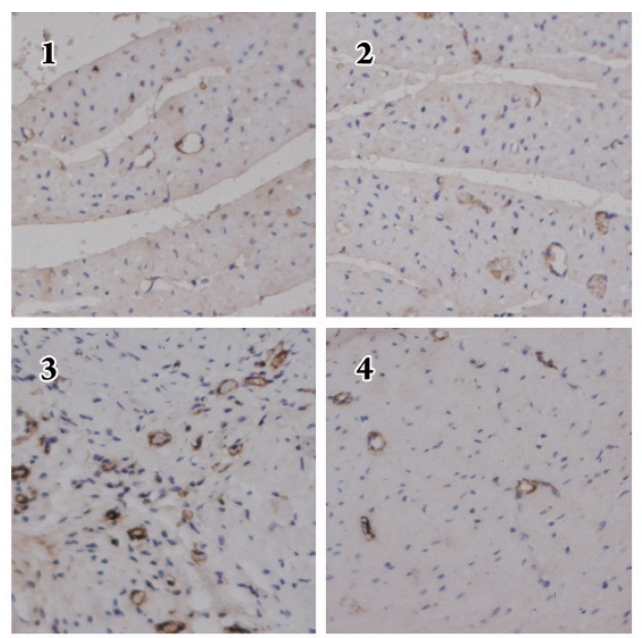

B

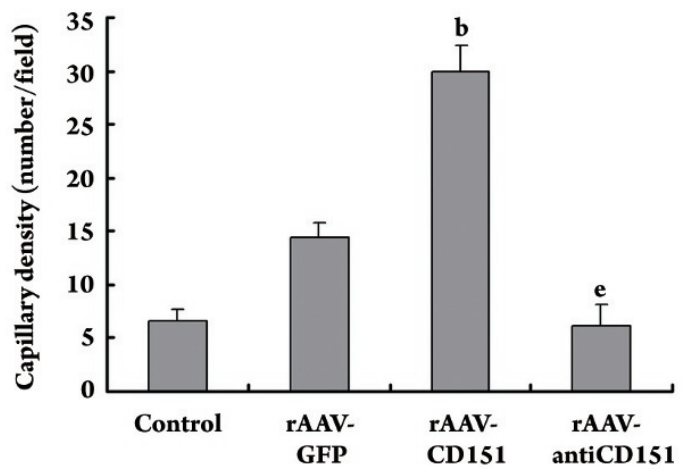

Figure 3. Capillary density in different groups. (A) Blood vessels were highlighted by immunostaining for vWF. The endothelial cells were dyed brown. 1, Control group; 2, rAAV-GFP group; 3 , rAAVCD151 group; 4, rAAV-antiCD151 group (magnification $\times 200$ ). (B) The density of total capillaries was dramatically increased in the rAAVCD151 group, whereas rAAV-antiCD151 group had decreased density. Data represent the mean of vessel number \pm SEM per field $(n=4-6)$. ${ }^{\mathrm{b}} P<0.05$ vs Control and rAAV-GFP groups. ${ }^{\mathrm{e}} \mathrm{P}<0.05 v \mathrm{vAAV}$-CD 151 group.

sity of total capillaries was dramatically higher in the rAAVCD151 group than in the Control group and rAAV-GFP group $(P<0.05)$, whereas rAAV-antiCD151 group had lower density compared with the rAAV-CD151 group $(P<0.05)$ (Figure 3). These data suggest that CD151 plays a critical role in the microvessels formation.

Effect of CD151 gene delivery on myocardial perfusion $\left[{ }^{13} \mathrm{~N}\right] \mathrm{NH}_{3} \mathrm{PET}$ images were divided into three different axis: short-axis images, vertical-axis images and horizontalaxis images (Figure 4A). Eight weeks after vector administration, Control group showed normal myocardium blood perfusion in pigs. There was no apparently reduced perfusion. Images of rAAV-GFP group typically demonstrated a characteristic reduced perfusion corresponding to the 


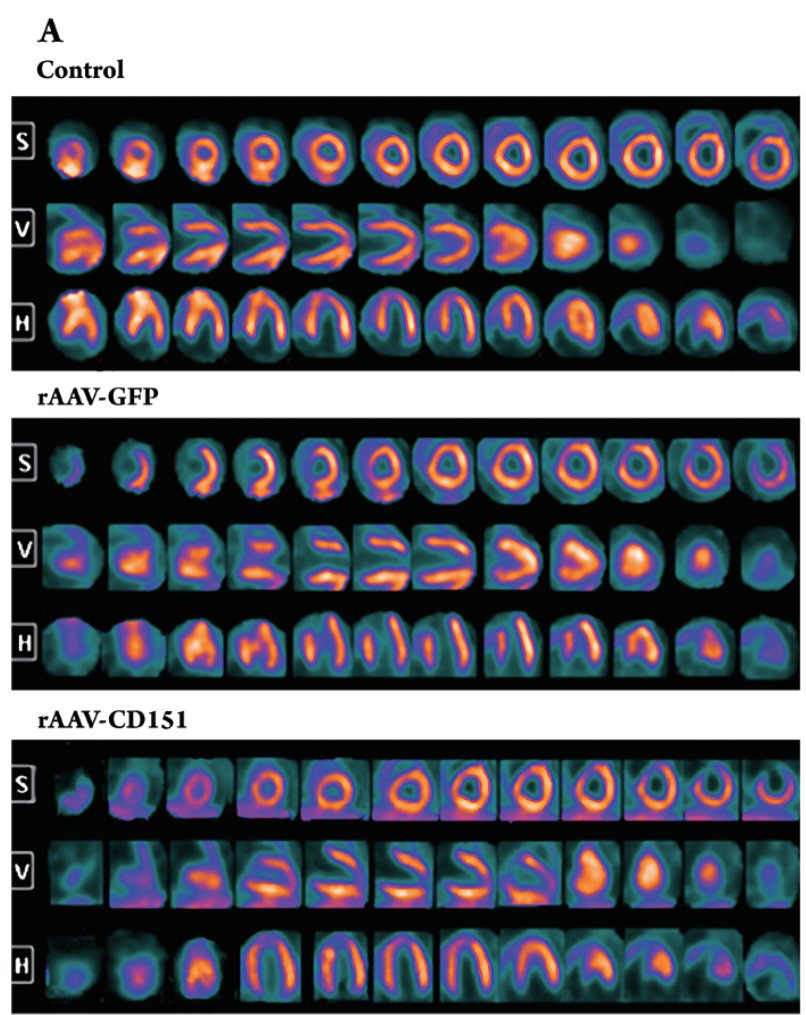

rAAV-antiCD151

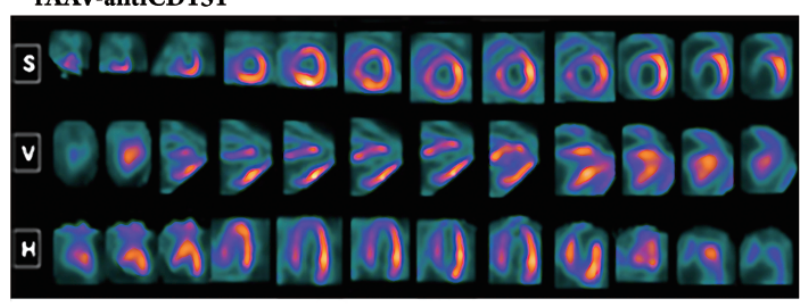

B

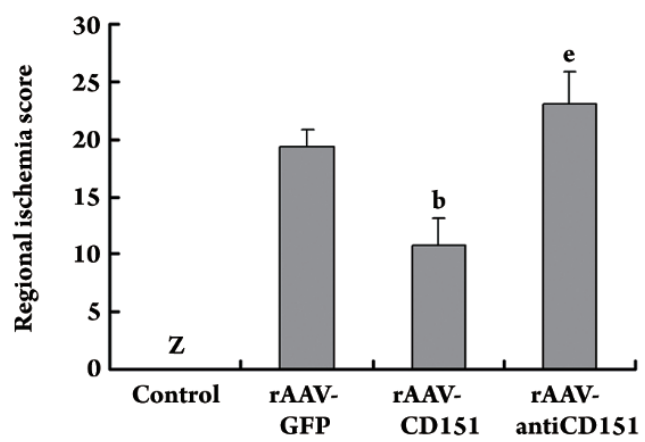

Figure 4. $\left[{ }^{13} \mathrm{~N}\right] \mathrm{NH}_{3} \mathrm{PET}$ images of myocardial perfusion in four different groups. S, short axis; V, vertical axis; H, horizontal axis. (A) Control group showed the myocardial blood perfusion in normal pigs. rAAV-GFP group demonstrated persistence of the ligation-induced perfusion defect. rAAV-CD151 group exhibited large improved blood perfusion. rAAV-antiCD151 group exhibited worse blood perfusion. (B) Regional ischemia scores. Z, zero ischemia score $(n=4-6)$. Data represent mean $\pm \operatorname{SEM}(n=4-6) .{ }^{b} P<0.05 v s$ rAAV-GFP group; ${ }^{\mathrm{e}} \mathrm{P}<0.05$ vs rAAV-CD151 group. These results showed CD151 gene transfection improved the myocardial blood perfusion. occluded distal LAD distribution: radioactivities of apical, left ventricular anterior wall and some septal wall displayed degraded distribution. rAAV-CD151 group exhibited improved myocardial blood perfusion in three axis, although there was still a little reduced radioactivity distribution in apical region. Images ofrAAV-antiCD151 group exhibited perfusion defect, and most images revealed hyperdispersion and decreased perfusion.

Regional ischemia scores were different in four groups. Control group showed zero ischemia score. rAAV-CD151 group demonstrated significantly lower regional ischemia score compared with rAAV-GFP group $(P<0.05$, Figure $4 \mathrm{~B})$. The regional ischemia score in $\mathrm{rAAV}$-antiCD151 group was much higher compared with rAAV-CD151 group $(P<0.05)$. Therefore, the CD151 gene transfection improves the blood perfusion.

Effect of CD151 gene delivery on myocardial defect area The cloud plots were constructed by nesting the ventricular short-axis image segments. There is no apparently defect in Control group. Three other groups showed different images. Their defect area was mainly at apical, anterior wall and septal wall (Figure 5A). In contrast, the defect area percentage was significantly lower in the rAAV-CD151 group than that in the rAAV-GFP group $(P<0.05)$, but greatly higher in the rAAV- antiCD151 group compared with the rAAVCD151 group $(P<0.05)$ (Figure $5 B)$. These results demonstrate that CD151 transfection reduces the defect area.

\section{Discussion}

The present study demonstrates that rAAV-mediated transfer of the cDNA of CD151 directly into the myocardium of pigs with an occluded LAD results in greatly increased microvessels and significant improvement in regional myocardial perfusion. Importantly, this improvement is associated with reduced regional myocardial ischemia and defect area. Hence, these data show that overexpression of CD151 promoted efficient neovascularization.

Angiogenesis is the formation of new blood vessels from preexisting vessels, a physiological or pathological neovascularization process in response to tissue ischemia and tumor growth or metastasis. The formation processes of new blood vessels involve endothelial migration and proliferation, extracellular proteolysis, endothelial differentiation (capillary tube formation), and vascular wall remodeling. When plated on basement membrane matrix (Matrigel), endothelial cells often form an anastomosing cellular network, which mimics in vivo angiogenesis. Data gathered from studies in vitro identify the function of CD151 in the endothelial cell 
A
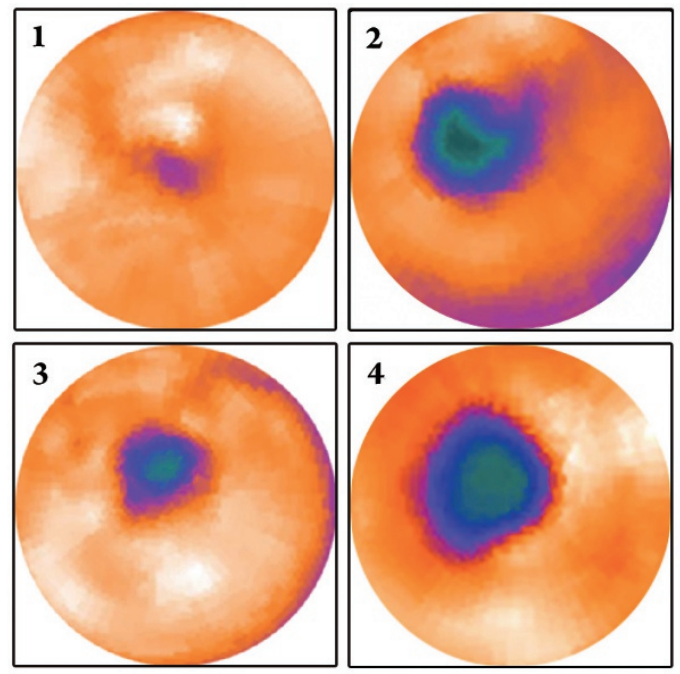

B

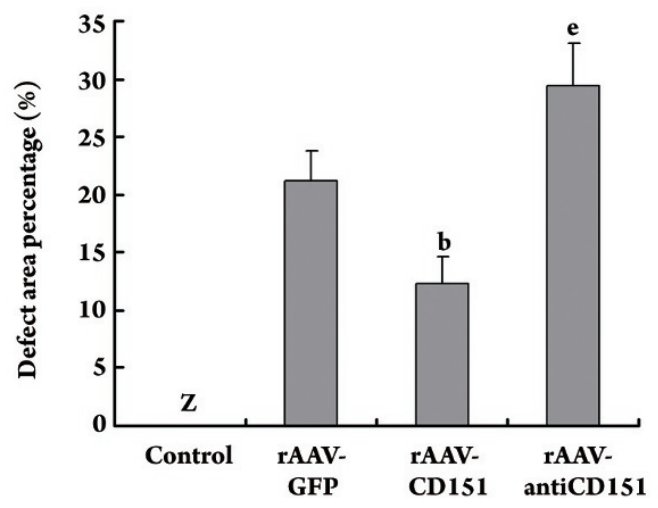

Figure 5. The clout plots showed defect area. (A) The clout plots were constructed by nestificating the ventricular short-axis image segments of $\left[{ }^{13} \mathrm{~N}\right] \mathrm{NH}_{3} \mathrm{PET}$. Control group demonstrated no apparently defect of normal pigs. rAAV-GFP, rAAV-CD151 and rAAV-anti-CD151 groups had defect area mainly in the apical, septal wall and anterior wall. 1, Control group; 2, rAAV-GFP group; 3, rAAV-CD151 group; 4, rAAVanti-CD151 group. (B) Quantitative analysis of the defect area. The defect area percentage was significantly decreased in the rAAV-CD151 group than that in the rAAV-GFP group. $Z$, the defect area percentage was zero. Data represent mean $\pm \operatorname{SEM}(n=4-6) .{ }^{b} P<0.05 v s$ rAAV-GFP group; ${ }^{\mathrm{e}} \mathrm{P}<0.05$ vs rAAV-CD 151 group.

migration, proliferation and cellular cable formation ${ }^{[6,8,10,11]}$. The appearance of cord-like structures on matrigel been disrupted by antibodies to CD151 (mAb 5C11) is seen in NIH3T3 cells and HUVECs ${ }^{[6,8]}$. In in vivo studies, our group has demonstrated that rAAV-mediated CD151 gene transfer stimulates the formation of capillaries and collateral vessels in a rat hind-limb ischemia model ${ }^{[14]}$; overexpression of CD151 increases the number of microvessels in the rat ischemic myocardium, significantly improves the hemodynamic variables after myocardial infarction at 4 weeks after coronary ligation $^{[13]}$. Thus, these studies suggest that CD151 contrib- utes to angiogenesis in particular and our choice of CD151 for this study is based on above findings.

In the present study, we further explored CD151-induced myocardial angiogenesis and focused on the myocardial blood perfusion in pig model, a large animal model useful for mimicking human heart pathology. Results showed the capillary density of rAAV-CD151 group was higher than Control and rAAV-GFP groups. In the rAAV-antiCD151 group, when the CD151 protein expression was decreased, the density of capillary was lower. This result was consistent with our early studies. However, newly formed capillary tubes lack vascular smooth muscle cells, which is unable to sustain proper circulation and adapt to changes in demands of blood supply ${ }^{[19]}$. Areas completely deprived of blood flow will undergo necrosis and form fibrous scar tissue in the healing process, whereas tissue receiving insufficient blood flow turns into a power save mode of hibernating, viable myocardium. Therefore, restoration of heart function is dependent on the restoration of blood flow ${ }^{[15]}$. Our results of $\left[{ }^{13} \mathrm{~N}\right] \mathrm{NH}_{3} \mathrm{PET}$ images showed myocardial blood perfusion was obviously improved in the rAAV-CD151 group and the defect area was reduced, but reversed changes happened in the rAAVantiCD151 group. Therefore, CD151 gene delivery can help to retrieve the myocardial blood perfusion, which is really helpful to compensate the blood loss because of coronary occlusion.

How could CD151-induced neovascularization promotes the blood flow? As we know, arteriogenesis is the rapid proliferation of preexisting collateral arteries. These arteries have the ability to increase the lumen by growth and to provide enhanced perfusion to the jeopardized ischemic regions ${ }^{[15,19]}$. So, except for angiogenesis, CD151 may induce arteriogenesis so as to promote the myocardial blood perfusion. On the other hand, CD151 may play critical roles in the maturation of capillaries. CD151 is reported to interact and activate matrix metalloproteinese-7 (MMP-7), to modulate the production and expression of MMP-2 and MMP- ${ }^{[20-22]}$. These MMPs play key roles in the degradation of basement membrane, which is an important step in the maturation of capillaries. The growth vessel from maturated capillaries, acquisition of smooth muscle cell coat, will be helpful to blood flow. Moreover, CD151 also forms an structural and functional complex with hepatocyte growth factor (HGF) receptor c-Met ${ }^{[23]}$. CD151 acts as a molecular controller for the signal pass through HGF/c-Met signalling pathway and influences the HGF-dependent phenomenons, which has been reported to improve collateral vessel growth in animal models of hindlimb and myocardial ischemia ${ }^{[2,24]}$. In this way, CD151 is likely to influence the function of other 
angiogenic factors, stimulate neovascularization and improve blood perfusion.

Our choice of an rAAV-mediated delivery strategy for the treatment of cardiac ischemia is based on the specific characteristics of rAAV vector. Genes encoding angiogenic factors can be delivered either nonvirally using plasmid constructs or using viral vectors. Plasmids are easy to produce and safe, but their main drawback in myocardium is a very low transduction efficiency ${ }^{[25]}$. rAAV vector holds a number of attractive features, including natural tropism to muscle tissue, lack of cytotoxicity, ability to transduce both dividing and non-dividing cells, and transgene expression lasting up to a year after gene transfer ${ }^{[26,27]}$. Our findings also indicate that rAAV is an efficient vector for in vivo transfer and that rAAVmediated CD151 gene transfer provides effective and longlasting expression of therapeutic genes into the myocardium.

In conclusion, the primary significance of the observations in the present study is that direct myocardial administration of an rAAV vector containing the CD151 cDNA enhanced myocardial perfusion and reduced the defect area. These data further support that CD151 promotes angiogenesis and CD151-induced neovascularization is a beneficial response after AMI to increase perfusion in the ischemic area. Together, our studies should shed light on the CD151 as a new therapeutic strategy for the treatment of ischemic cardiovascular diseases.

\section{Acknowledgement}

Project was supported by grants from the National Natural Science Foundation of China (№ 30570728; № 30670856).

We thank Dr Xin ZHANG for providing PzeoSV-CD151 plasmid and Dr Xiao XIAO (University of Pittsburgh, PA, USA) for providing us with dsAAV-GFP, pXX2, phelper.

\section{Author contribution}

Zheng-xiang LIU designed the research; Hou-juan ZUO performed the research, analyzed data and wrote the paper; Xiao-chun LIU performed the research and analyzed data; Jun YANG, Tao LIU, and Sha WEN performed the research; Dao-wen WANG contributed new reagents and analytical tools; Xin ZHANG contributed new reagents.

\section{References}

1 Lee LY, Patell SR, Hackett NR, Mack CA, Polce DR, El-Sawy T, et al. Focal angiogen therapy using intramyocardial delivery of an adenovirus vector coding for vascular endothelial growth factor 121. Ann Thorac Surg 2000; 69: 14-23.

2 Taniyama Y, Morishita R, Aoki M, Nakagami H, Yamamoto K, Yamazaki $\mathrm{K}$, et al. Therapeutic angiogenesis induced by human hepatocyte growth factor gene in rat and rabbit hindlimb ischemia models: preclinical study for treatment of peripheral arterial disease. Gene Ther 2001; 8: 181-9.

3 Fitter S, Tetaz TJ, Berndt MC, Ashman LK. Molecular cloning of cDNA encoding a novel platelet-endothelial cell tetra-span antigen, PETA-3. Blood 1995; 86: 1348-55.

4 Hasegawa H, Utsunomiya Y, Kishimoto K, Yanagisawa K, Fujita S. SFA-1, a novel cellular gene induced by human T-cell leukemia virus type 1 , is a member of the transmembrane 4 superfamily. J Virol 1996; 70: 3258-63.

5 Sincock PM, Mayrhofer G, Ashman LK. Localization of the transmembrane 4 superfamily (TM4SF) member PETA-3 (CD151) in normal human tissues: comparison with CD9, CD63, and alpha5beta1 integrin. J Histochem Cytochem 1997; 45: 515-25.

6 Sincock PM, Fitter S, Parton RG, Berndt MC, Gamble JR, Ashman LK. PETA-3/CD151, a member of the transmembrane 4 superfamily, is localised to the plasma membrane and endocytic system of endothelial cells, associates with multiple integrins and modulates cell function. J Cell Sci 1999; 112: 833-44.

7 Yauch RL, Berditchevski F, Harler MB, Reichner J, Hemler ME. Highly stoichiometric, stable, and specific association of integrin alpha3beta 1 with CD 151 provides a major link to phosphatidylinositol 4-kinase, and may regulate cell migration. Mol Biol Cell 1998; 9: 2751-65.

8 Zhang XA, Kazarov AR, Kazarov AR, Yang X, Bontrager AL, Stipp CS, et al. Function of the tetraspanin CD151-alpha6betal integrin complex during cellular morphogenesis. Mol Biol Cell 2002; 13: $1-11$.

9 Hemler ME. Integrin-associated proteins. Curr Opin Cell Biol 1998; 10: 578-85.

10 Yáñez-Mó M, Alfranca A, Cabañas C, Marazuela M, Tejedor R, Ursa MA, et al. Regulation of endothelial cell motility by complexes of tetraspan molecules CD81/TAPA-1 and CD151/PETA-3 with alpha3 beta1 integrin localized at endothelial lateral junctions. J Cell Biol 1998; 141: 791-804.

11 Zheng ZZ, Liu ZX. Activation of the phosphatidylinositol 3-kinase/protein kinase Akt pathway mediates CD151-induced endothelial cell proliferation and cell migration. Int J Biochem Cell Biol 2007; 39: 340-8.

12 Zheng ZZ, Liu ZX. CD151 gene delivery increases eNOS activity and induces ECV304 migration, proliferation and tube formation. Acta Pharmacol Sin 2007; 28: 66-72.

13 Zheng ZZ, Liu ZX. CD151 gene delivery activates PI3K/Akt pathway and promotes neovascularization after myocardial infarction in rats. Mol Med 2006; 12: 214-20.

14 Lan RF, Liu ZX, Liu XC, Song YE, Wang DW. CD151 promotes neovascularization and improves blood perfusion in a rat hindlimb ischemia model. J Endovasc Ther 2005; 12: 469-78.

15 Markkanen JE, Rissanen TT, Kivelä A, Ylä-Herttuala S. Growth factor-induced therapeutic angiogenesis and arteriogenesis in the heart-gene therapy. Cardiovasc Res 2005; 65: 656-64.

16 Lan R, Liu Z, Song YE, Zhang X. Effects of rAAV-CD151 and rAAV-antiCD151 on the migration of human tongue squamous carcinoma cell line Tca8113. J Huazhong Univ Sci Technol Med 
Sci 2004; 24: 556-9.

17 Xiao X, Li J, Samulski RJ. Production of high-titer recombinant adeno-associated virus vectors in the absence of helper adenovirus. J Virol 1998; 72: 2224-32.

18 Weidner N, Folkman, Pozza F, Bevilacqua P, Allred EN, Moore $\mathrm{DH}$, et al. Tumor angiogenesis: a new significant and independent prognostic indicator in early-stage breast carcinoma. J Natl Cancer Inst 1992; 84: 1875-87.

19 Buschmann I, Schaper W. Arteriogenesis versus angiogenesis: two mechanism of vessel growth. News Physiol Sci 1999; 14: 121-5.

20 Hong IK, Jin YJ, Byun HJ, Jeoung DI, Kim YM, Lee H. Homophilic interactions of Tetraspanin CD151 up-regulate motility and matrix metalloproteinase-9 expression of human melanoma cells through adhesion-dependent c-Jun activation signaling pathways. J Biol Chem 2006; 281: 24279-92.

21 Sugiura T, Berditchevski F. Function of alpha3beta1-tetraspanin protein complexes in tumor cell invasion. Evidence for the role of the complexes in production of matrix metalloproteinase 2 (MMP-2). J Cell Biol 1999; 146: 1375-89.

22 Shiomi T, Inoki I, Kataoka F, Ohtsuka T, Hashimoto G, Nemori $\mathrm{R}$, et al. Pericellular activation of proMMP-7 (promatrilysin-1) through interaction with CD151. Lab Invest 2005; 85: 1489-506. 23 Klosek SK, Nakashiro K, Hara S, Shintani S, Hasegawa H, Hamakawa H. CD151 forms a functional complex with c-Met in human salivary gland cancer cells. Biochem Biophys Res Commun 2005; 336: 408-16.

24 Aoki M, Morishita R, Taniyama Y, Kida I, Moriguchi A, Matsumoto $\mathrm{K}$, et al. Angiogenesis induced by hepatocyte growth factor in noninfarcted myocardium and infarcted myocardium: up-regulation of essential transcription factor for angiogenesis. Gene Ther 2000; 7 : 417-27.

25 Rutanen J, Rissanen TT, Markkanen JE, Gruchala M, Silvennoinen $\mathrm{P}$, Kivela A, et al. Adenoviral catheter-mediated intramyocardial gene transfer using the mature form of vascular endothelial growth factor-D induces transmural angiogenesis in porcine heart. Circulation 2004; 109: 1029-35.

26 Gruchala M, Bhardwaj S, Pajusola K, Roy H, Rissanen TT, Kokina I, et al. Gene transfer into rabbit arteries with adeno-associated virus and adenovirus vectors. J Gene Med 2004; 6: 545-54.

27 Wang Z, Ma HI, Li J, Sun L, Zhang J, Xiao X. Rapid and highly efficient transduction by double-standed adeno-associated virus vectors in vitro and in vivo. Gene Ther 2003; 10: 2105-11. 